\title{
Patient safety culture regarding intravenous therapy in Guangzhou, China: a cross-sectional survey
}

Cui-Hong Jia, ${ }^{a}$, Fei-Hua Xuª, Shan Pan ${ }^{b}$

aNursing Department, The Second Affiliated Hospital of Guangzhou Medical University, Guangzhou, Guangdong 510260, China

${ }^{b}$ Department of Oncology, The Second Affiliated Hospital of Guangzhou Medical University, Guangzhou, Guangdong 510260, China

Received: 14 May 2019; Accepted: 2 July 2019; Published: 20 December 2019

\begin{abstract}
Objective: To investigate the patient safety culture regarding intravenous therapy in parts of tertiary hospitals in Guangzhou, China. Methods: A cross-sectional survey was conducted. A total of 333 medical staffs members from eight hospitals in Guangzhou were included in our study using convenience sampling. An evaluation about the patient safety culture regarding intravenous therapy was conducted. Results: The summarized results show that the total and level one items' scores are greater than 4.3 points (the full mark is 5 points). The lowest scoring of the five level one items is for the hospital's security resources (4.53 \pm 0.526$)$, and the highest is for the hospital's safety management commitment $(4.65 \pm 0.445)$. Among the 25 secondary entries, the four lowest-scoring entries are "doctors who can master the knowledge of drug efficacy and adverse reactions" (4.44 \pm 0.622$)$, "doctors who can master the knowledge of the choice of medicine" ( $4.45 \pm 0.621)$, "a guarantee of sufficient human resources" (4.46 \pm 0.647$)$, and "doctors who can master the knowledge related to the observation and complications with the treatment of intravenous therapy operation" $(4.435 \pm 0.634)$. Conclusions: The patient safety culture regarding intravenous treatment in parts of tertiary hospitals in Guangzhou is promising, but there are still shortcomings, including the need to increase relevant resources, such as equipment facilities, training resources, and especially human input.
\end{abstract}

Keywords: intravenous therapy $\bullet$ patient $\bullet$ safety culture $\bullet$ survey $\bullet$ hospital

(c) Shanxi Medical Periodical Press.

\section{Introduction}

In 1999, the Institute of Medicine (IOM), after three major medical accidents, published a landmark report:1 "To Err is Human: Building a Safer Health System" (translated as "everyone makes mistakes: building a safer health care system"). The IOM thinks that the objective of patient safety is to allow patients to avoid accidental injury to ensure the safety of patients. It requires that medical institutions, through the establishment of standardized procedures and systems, maximize the prevention of the occurrence of errors. Patient safety culture, which is also called patient safety climate, is the overall behavior of individuals and organizations based on common beliefs and values, which refer to a common attitude, belief, value, and behavior pattern of medical organizations and institutions. ${ }^{2,3}$ Studies ${ }^{4-6}$ show that the improvement in the quality of medical care and patient safety is closely related to a patient's consciousness of a good culture, and a positive safety culture can promote patient safety, can increase the satisfaction of patients about the hospital and can improve the patient's medical experience..$^{7,8}$ To date, many

How to cite this article: Ji CH, Xu FH, Pan S. Patient safety culture regarding intravenous therapy in Guangzhou, China: a cross-sectional survey. Front Nurs. 2019; 4: 335-340. 
countries have initiated patient safety culture research, 9,10 especially developed countries. ${ }^{8,11-13}$ Some scales have been designed, ${ }^{2}$ such as the Patient Safety Climate in Healthcare Organizations (PSCHO) in America, which evaluates the status of the patient safety culture in medical institutions. It is meant to help understand the security level and the state of the whole unit through an assessment of the staff's attitude toward patient safety in order to create a positive safety culture through the measurement of the safety culture. ${ }^{14}$ However, this has just begun in China; a majority of the hospitals have only established an opinion collection system for in-hospital patients and a follow-up system for discharged patients, and there is a lack of a patient safety culture assessment regarding intravenous therapy.

The scale of intravenous treatment in China is very large, and there are many complex risk factors throughout the process. ${ }^{15}$ There are many risk factors about safe trouble, such as drug allocation of taboo, dispensing particle pollution, lack of observation by nurses, and lack of static cure protection knowledge of evaluate, patient safety goals for intravenous treatment is wrong, and so on. An important reason for these problems is that medical staff and patients have not established a unified and internalized patient safety culture regarding intravenous therapy. China has also developed a corresponding intravenous therapy nursing technical operation standard ${ }^{16}$ and practice. There is related research, ${ }^{17}$ which took a survey on the status quo of intravenous treatment and care in 147 hospitals and a total of 584 departments in 27 provinces of China. The results showed that the intravenous therapy specialisation has rapidly developed but is still exposed to some problems. The scale of intravenous treatment in China is very large. Patient safety culture regarding intravenous treatment will play an important role in improving the quality of intravenous therapy; the construction of safety culture of intravenous therapy is particularly important.

Therefore, if hospitals want to improve patient safety, it is important to know more about the culture regarding patient safety. In this study, through a questionnaire survey of doctors, nurses and patients from different tertiary-level hospitals in Guangzhou, China, we aimed to understand the patient safety culture status regarding intravenous treatment from different angles and to provide scientific evidence for the development of effective measures to enhance the patient safety culture regarding intravenous treatment.

\section{Methods}

\subsection{Design and sample}

In this study, doctors and nurses from eight tertiary hospitals in Guangzhou were selected. All the doctors and registered nurses of this study were working in these hospitals. All the hospitals were tertiary hospitals in Guangzhou, China. The eight hospitals had an average bed capacity of 850 . The questionnaires were distributed by a convenience sampling method in the eight hospitals. A total of 400 questionnaires were issued, and responses were received from 356 participants. There were 333 valid questionnaires, and the effective recovery rate was $83.3 \%$.

\subsection{Instrument}

\subsubsection{General information questionnaire}

The general information of the questionnaire designed by our team included the general demographic data of the study, the development of the hospital intravenous therapy, etc.

\subsubsection{Evaluation table for patient safety culture regarding intravenous therapy}

The evaluation table for patient safety culture regarding intravenous therapy ${ }^{18}$ was adopted based on an expert consultation. First, the recent literature about patient safety culture was read, including the $\mathrm{PSCHO},{ }^{2}$ developed by the medical institutions of Boston University, and related research. ${ }^{19}$ Then, after two rounds of expert consultation by 36 experts in intravenous therapy from the hospitals in Guangzhou, we used a preliminary evaluation system, which contained a total of 25 secondary entries belonging to five level one entries, including the hospital's safety management commitment, the hospital's security resources, the hospital's atmosphere of safety culture, the degree of knowledge mastery of intravenous therapy, and the staff's beliefs and behaviors regarding intravenous therapy safety. We established the evaluation table for patient safety culture regarding intravenous therapy according to the 25 entries of the system. Before using the table, we conducted a reliability and validity test. The results show that the total internal consistency coefficient of the evaluation table was 0.964 . In addition, the internal consistency coefficients of all the dimensions were from 0.873 to 0.964 , and they were all greater than 0.7 . Thus, we demonstrated that this scale had a high internal coefficient consistency. The test-retest reliability of the table was 0.813 . The average Content Validity Index (CVI) of all entries was 0.907 , and the results of the exploratory factor analysis showed that the evaluation table had a good structure validity. Therefore, we can use this table to investigate the patient safety culture regarding intravenous therapy. 


\subsection{Statistical analysis}

The data management and analysis were conducted using SPSS Statistics 20.0. Data were expressed as mean (SD). $P<0.05$ was considered as statistically significant. All the data were de-identified and organized by the questionnaire identification numbers. Descriptive statistical analyses, such as the frequencies and percentages of positive responses for each entry and dimension, were used to show age, work age, educational degree, position at the hospital, and score of intravenous therapy patient safety culture. Two-tailed independent $t$-test comparisons of the sample mean values were used to compare the scores of the patient safety culture regarding intravenous therapy between the medical staff and the patients.

\section{Results}

\subsection{General information about subjects}

The sample comprised 333 respondents from the eight tertiary hospitals in Guangzhou, China, including two provincial hospitals, five municipal hospitals and one military hospital. The mean age of the participants was 30.07 years $(S D=7.144)$. There were 333 medical staffs, including 98 (29.5\%) doctors and 235 (70.5\%) nurses, of which one was missing; there were 69 males $(21.2 \%)$ and 256 females $(78.8 \%)$, of which eight were missing; The educational structure of the study subjects was as follows: five $(1.5 \%)$ subjects had technical secondary school education, $80(24.0 \%)$ had college degree, $193(58.0 \%)$ had bachelor degree, 44 (13.2\%) had master's degree, and $11(3.3 \%)$ had doctor's degree. In all, 256 (63.8\%) participants were female. Among the medical staff, $5.7 \%$ did not know whether the hospital had established an intravenous therapy nursing team, $6 \%$ were not clear about whether the departments carried out transfusion tube placement, $3 \%$ were not clear about whether the departments carried out peripherally inserted central catheter (PICC), 4.8\% did not know whether the hospital had an intravenous therapy nurse specialist, and $10.2 \%$ did not know whether the hospital had opened a catheter nursing outpatient unit. Subjects who were very familiar with and familiar with intravenous therapy accounted for $24.6 \%$ and $53.2 \%$, respectively.

\subsection{Status of patient safety culture regarding intravenous therapy}

The total, the first level, and the second level scores of the culture score of safety of intravenous therapy are shown in Table 1. The evaluation table for patient safety culture regarding intravenous therapy used a 5-point Likert scale as follows: very poor (1 point), poor (2 points), moderate (3 points), good (4 points), and very good (5 points), and each item score ranged from 1 to 5 . The summarized results show that the total and level one items' scores are greater than 4.3 points (the full mark is 5 points). The lowest scoring of the five level one items is for the hospital's security resources $(4.53 \pm 0.526)$, and the highest is for the hospital's safety management commitment $(4.65 \pm 0.445)$. Among the 25 secondary entries, the four lowest-scoring entries are "doctors who can master the knowledge of drug efficacy and adverse reactions "(4.44 \pm 0.622$)$, "doctors who can master the knowledge of the choice of medicine" $(4.45 \pm 0.621)$, "a guarantee of sufficient human resources" (4.46 \pm 0.647 ), and "doctors who can master the knowledge related to the observation and complications with the treatment of intravenous therapy operation" (4.435 \pm 0.634$)$.

\section{Discussion}

\subsection{Patient safety culture regarding intravenous therapy is promising overall}

This investigation included two provincial, five municipal, and one unit 3 armor hospital. The sample size of the survey is quite, and the results have certain representativeness. From Table 1, we can see that the total point, level one items, and the secondary entries' scores of safety culture are greater than 4.3 points (the full mark is 5 points). We can know that the situation of 3 armor hospital's intravenous treatment safety culture of Guangzhou is more optimistic. The objectives of patient safety culture assessment were to diagnose hospital's patient safety, to determine the key factors to improve patient safety, to evaluate the effects of safety interventions through the comparison of the baseline and after intervention, and to provide targeted improvement opinions or suggestions. ${ }^{3}$ This assessment of intravenous treatment safety culture shows that the 3 armor hospitals in Guangzhou had played a good effect in promoting the intravenous treatment safety culture through constant efforts of relevant policies and system support.

\subsection{Investment of manpower and training still need to be strengthened}

Patient safety culture assessment, feedback, and targeted improvement are effective ways to improve patient safety culture,$^{20}$ and fostering positive safety culture has become a necessary measure for the continual improvement of the patient safety. From Table 1, we can know that, the lowest secondary entries were a guarantee 


\begin{tabular}{|c|c|c|c|}
\hline Entries & Staff & Entries & Staff \\
\hline $\begin{array}{l}\text { 1. The hospital's safety management } \\
\text { commitment }\end{array}$ & $4.65 \pm 0.45$ & $\begin{array}{l}\text { 4. The degree of knowledge mastery of intravenous } \\
\text { therapy }\end{array}$ & $4.50 \pm 0.50$ \\
\hline $\begin{array}{l}\text { 1.1. Attaching great importance to intravenous } \\
\text { therapy safety }\end{array}$ & $4.70 \pm 0.50$ & $\begin{array}{l}\text { 4.1. Doctors who can master the knowledge of drug } \\
\text { efficacy and adverse reactions }\end{array}$ & $4.44 \pm 0.62$ \\
\hline $\begin{array}{l}\text { 1.2. Having a perfect system and provisions for } \\
\text { intravenous therapy safety }\end{array}$ & $4.64 \pm 0.52$ & $\begin{array}{l}\text { 4.2. Doctors who can master the knowledge of the } \\
\text { choice of medicine }\end{array}$ & $4.45 \pm 0.62$ \\
\hline $\begin{array}{l}\text { 1.3. Timely management of safety problems and } \\
\text { hidden dangers of intravenous therapy }\end{array}$ & $4.63 \pm 0.51$ & $\begin{array}{l}\text { 4.3. Doctors who can master the knowledge related } \\
\text { to the observation and complications with the } \\
\text { treatment of intravenous therapy operation }\end{array}$ & $4.47 \pm 0.61$ \\
\hline $\begin{array}{l}\text { 1.4. Having a penalty-free reporting system of } \\
\text { intravenous therapy safety problems }\end{array}$ & $4.59 \pm 0.56$ & $\begin{array}{l}\text { 4.4. Doctors who can master the knowledge related } \\
\text { to observing and treating the adverse reactions } \\
\text { to transfusion }\end{array}$ & $4.54 \pm 0.54$ \\
\hline 2. The hospital's security resources & $4.53 \pm 0.53$ & $\begin{array}{l}\text { 4.5. Nurses who can master the knowledge related } \\
\text { to infusion tool selection }\end{array}$ & $4.52 \pm 0.56$ \\
\hline $\begin{array}{l}\text { 2.1. Hospital having a clear plan and treatment } \\
\text { methods for intravenous therapy safety }\end{array}$ & $4.59 \pm 0.53$ & $\begin{array}{l}\text { 4.6. Nurses who can master the knowledge related } \\
\text { to observing and treating the adverse reactions } \\
\text { of transfusion }\end{array}$ & $4.52 \pm 0.55$ \\
\hline $\begin{array}{l}\text { 2.2. Having adequate equipment and facilities to } \\
\text { ensure intravenous therapy safety }\end{array}$ & $4.53 \pm 0.59$ & $\begin{array}{l}\text { 4.7. Nurses who can master the knowledge related } \\
\text { to catheter maintenance }\end{array}$ & $4.50 \pm 0.58$ \\
\hline 2.3. A guarantee of sufficient human resources & $4.46 \pm 0.65$ & $\begin{array}{l}\text { 5. The staff's beliefs and behaviors regarding } \\
\text { intravenous therapy safety }\end{array}$ & $4.54 \pm 0.50$ \\
\hline $\begin{array}{l}\text { 2.4. Having training opportunities to improve } \\
\text { the safety knowledge and awareness of the } \\
\text { intravenous treatment for employees }\end{array}$ & $4.50 \pm 0.62$ & $\begin{array}{l}\text { 5.1. Doctors who can choose a reasonable method } \\
\text { of drug use }\end{array}$ & $4.45 \pm 0.64$ \\
\hline $\begin{array}{l}\text { 3. The hospital's atmosphere of patient safety } \\
\text { culture }\end{array}$ & $4.54 \pm 0.51$ & $\begin{array}{l}\text { 5.2. Doctors who can observe the complications } \\
\text { and adverse reactions of intravenous therapy } \\
\text { timely and effectively }\end{array}$ & $4.54 \pm 0.58$ \\
\hline $\begin{array}{l}\text { 3.1. Having the habit of evaluating intravenous } \\
\text { therapy safety }\end{array}$ & $4.54 \pm 0.57$ & 5.3. Checking the intravenous therapy for nurses & $4.61 \pm 0.53$ \\
\hline $\begin{array}{l}\text { 3.2. Being able to assist the team to ensure } \\
\text { intravenous therapy safety }\end{array}$ & $4.58 \pm 0.54$ & $\begin{array}{l}\text { 5.4. Nurses who can perform active infusion in the } \\
\text { process of intravenous therapy }\end{array}$ & $4.50 \pm 0.65$ \\
\hline $\begin{array}{l}\text { 3.3. Having a positive response about the topic of } \\
\text { intravenous therapy safety }\end{array}$ & $4.50 \pm 0.62$ & $\begin{array}{l}\text { 5.5. Nurses who can observe the complications and } \\
\text { adverse reactions of intravenous therapy timely } \\
\text { and effectively }\end{array}$ & $4.56 \pm 0.56$ \\
\hline $\begin{array}{l}\text { 3.4. An active sharing atmosphere for the safety } \\
\text { problems and hidden dangers of intravenous } \\
\text { therapy }\end{array}$ & $4.50 \pm 0.61$ & $\begin{array}{l}\text { 5.6. Patients who can master and apply the } \\
\text { knowledge of health education }\end{array}$ & $4.54 \pm 0.60$ \\
\hline Total score & $4.56 \pm 0.46$ & & \\
\hline
\end{tabular}

Table 1. The total and entry scores of the patient safety culture regarding intravenous therapy $(M \pm S D)(N=333)$.

of sufficient human resources $(4.446 \pm 0.647)$. Some studies $^{21,22}$ had proved that plenty of human resources is a key factor to build a hospital safety culture, which can effectively improve patient safety. So we need to achieve rational allocation of clinical nurses and reasonable adjustment of working time. However, at present, China's medical institutions, especially the 3 armor hospitals, have widespread shortage of nurses, and the resource is not sufficient. A large number of hospitalized patients, a rapid turnover, complex patients, and a large number of intravenous infusion result in a large workload for the nurses, which indirectly leads to a shortage of human resources. Therefore, if we want to enhance the patient safety culture of intravenous therapy, first, we need to focus on strengthening the investment in human resources, especially nurses, and in departments with a large workload, such as the department of gastrointestinal surgery, the department of hepatobiliary surgery, and the department of oncology, and the ratio of nursing beds needs to improve to increase human input.

\subsection{Formation of active sharing mechanism of adverse events is necessary}

The scores of two items, doctors who can master the knowledge of drug efficacy and adverse reactions and doctors who can master the knowledge of the choice of medicine, were low, and this is partly because of the great variety of clinical medicines and the complicated effect of medicines, and thus, it is difficult to grasp. There is not a good patient safety culture regarding intravenous therapy because the doctors do not pay attention to building a safety culture. So we need to enhance the doctors' mastery about the knowledge related to intravenous drugs by training and assessments in order to strengthen safety, and we also must establish appropriate incentive policies and build a patient safety culture regarding intravenous therapy. In addition, we need to emphasize the active sharing of experiences about the safety problems and hidden dangers in the work process in order to absorb the experience and reduce the incidence of adverse events associated with intravenous 
treatment. We can build a safety culture to guide practice only through the improvement of many aspects to ensure the safety of patients.

\subsection{Awareness of intravenous therapy professional development of the medical staff needs to be improved}

Recently, many researchers ${ }^{18,23}$ have investigated the status of professional development in intravenous therapy in various regions in order to understand the problems and to provide a reference for continuous improvement. In this study, there are eight hospitals, which are all tertiary hospitals, and all have an intravenous team, all have PICC, all have carried out transfusion port placements, all have specialized nurses in intravenous therapy, and all have catheter care clinics, and the results are consistent with the relevant research. ${ }^{18}$ Among the medical staff, 5.7\% did not know whether the hospital had established an intravenous therapy nursing team, $6 \%$ were not clear about whether the departments carried out transfusion tube placement, $3 \%$ were not clear about whether the departments carried out PICC, $4.8 \%$ did not know whether the hospital had an intravenous therapy nurse specialist, and $10.2 \%$ did not know whether the hospital had opened a catheter nursing outpatient, and those who were very familiar with intravenous therapy and familiar with intravenous therapy accounted for $24.6 \%$ and $53.2 \%$, respectively. Therefore, it is necessary to strengthen the awareness of the relevant information so that the hospital staff can fully grasp the relevant information, such as the development of the professional scale in intravenous therapy. It is useful to promote the construction of a patient safety culture regarding intravenous therapy.

\section{Conclusions}

This study provides an assessment of the patient safety culture regarding intravenous therapy. Our results indicate that the overall situation is more promising, but there are still shortcomings, such as a need to increase the relevant resources, equipment facilities, training resources, and especially human input. The awareness of intravenous therapy professional development of the medical staff needs to be improved.

\section{Shortcomings and prospects}

This study only investigated the status of patient safety culture regarding intravenous therapy in tertiary hospitals of Guangzhou through the current situation survey. There was not an analysis of the relevant factors of the current situation, resulting in poor reliability. The followup plan is to analyze the important influencing factors of intravenous therapy safety culture by increasing the sample size, so as to provide reference for the subsequent improvement.

\section{Acknowledgments}

The authors gratefully acknowledge the supervisors and all employees who participated in this study for their assistance, as well as the experts and members of their group for their help and advice.

\section{Ethical approval}

The study protocol and instrument were reviewed and approved by the institutional review boards of the eight hospitals where the study was carried out. Participation was voluntary, and the identity of the participants was kept confidential by assigning questionnaire identification numbers. The questionnaire did not collect any information that could be used to identify the participants. Confidentiality was maintained at every stage of the study.

\section{Conflict of interest}

This paper is not being considered for publication elsewhere. No conflict of interest exists in the submission of this manuscript.

\section{References}

1. Kohn LT, Corrigan JM, Donaldson MS. To Err is Human:BuildingA SaferHealth System. Washington, DC: National Academies Press; 2000.

2. Singer SJ, Gaba DM, Geppert JJ, Sinaiko AD, Howard SK, Park KC. The culture of safety: results of an organization-wide survey in 15 California hospitals. Qual Safety Health Care. 2003;12:112-118.
3. Nieva VF, Sorra J. Safety culture assessment: a tool for improving patient safety in healthcare organizations. Qual Saf Health Care. 2003; 12(suppl II):ii17-ii23.

4. Dicuccio $\mathrm{MH}$. The relationship between patient safety culture and patient outcomes: a systematic review. J Patient Saf. 2015;11:135-142. 
5. Mardon RE, Khanna K, Sorra J, Dyer N, Famolaro T. Exploring relationships between hospital patient safety culture and adverse events. J Patient Saf. 2010;6:226-232.

6. Wang X, Liu K, You LM, et al. The relationship between patient safety culture and adverse events: a questionnaire survey. Int J Nur Stud. 2014;51:1114-1122.

7. Muething SE, Goudie A, Schoettker PJ, et al. Quality improvement initiative to reduce serious safety events and improve patient safety culture. Pediatrics. 2012;130:423-431.

8. Sorra J, Khanna K, Dyer N, Mardon R, Famolaro T. Exploring relationships between patient safety culture and patients' assessments of hospital care. J Patient Saf. 2012;8:131-139.

9. Smits M, Wagner C, Spreeuwenberg P, Timmermans DRM, van der Wal G, Groenewegen PP. The role of patient safety culture in the causation of unintended events in hospitals. J Clin Nurs. 2012;21:3392-3401.

10. Wami SD, Demssie AF, Wassie MM, Ahmed AN. Patient safety culture and associated factors: a quantitative and qualitative study of healthcare workers' view in Jimma zone Hospitals, Southwest Ethiopia. BMC Health Serv Res. 2016;16:495.

11. Bagnasco A, Tibaldi L, Chirone P, Sasso L. Patient safety culture: an Italian experience. J Clin Nurs. 2011;20:1188-1195.

12. Hammer A, Ernstmann N, Ommen O, et al. Psychometric properties of the Hospital Survey on Patient Safety Culture for hospital management (HSOPS_M). BMC Health Serv Res. 2011;11:1273-1273.

13. Ito S, Seto K, Kigawa M, Fujita S, Hasegawa T, Hasegawa T. Development and applicability of Hospital Survey on Patient Safety Culture (HSOPS) in Japan. BMC Health Serv Res. 2011;11:1-7.

14. Gimenes FR, Torrieri MC, Gabriel CS, et al. Applying an ecological restoration approach to study patient safety culture in an intensive care unit. J Clin Nurs. 2016;25:1073-1085.

15. Tian M, Liu F, Tao JR, Song HX. The nursing organizational factors that impact patient safety and weight analysis. Chin J Nurs. 2014;49:695-696 (in Chinese).

16. National Health and Family Planning Commission of the People's Republic of China. Nursing Practice Standard for Intravenous Therapy; 2013. Accessed 15October 2019. http://117.128.6.11/cache/www.nhc.gov.cn/ ewebeditor/uploadfile/2014/12/20141212142815390. PDF?ich_args2=462-15193212052239_559547b31c d410b12afd81ad47582cd5_10001002_9c89632dd6 c0f8d09232518939a83798_2b60445203e24f52c7ae 6f8baf2925b9.

17. Sun H, Wang L, Guan X, Nie SX. A survey of the status of infusion therapy in tertiary hospitals in China. Chin J Nurs. 2014;1232-1237 (in Chinese).

18. Ji CH, Xu FH, Pan S. Construction of safety culture evaluation system for intravenous treatment. Mod Clin Nurs. 2016;15:59-63 (in Chinese).

19. Hartmann CW, Rosen AK, Meterko M, et al. An overview of patient safety climate in the VA. Health Serv Res. 2008;43:1263-1284.

20. Weaver SJ, Lubomksi LH, Wilson RF, Pfoh ER, Martinez KA, Dy SM. Promoting a culture of safety as a patient safety strategy: a systematic review. Ann Intern Med. 2013;158:369-374.

21. Aiken L, Douglas M, Sloane D, et al. Nurse staffing and education and hospital mortality in nine European countries: a retrospective observational study. Lancet. 2014;383:1824-1830.

22. Kuntz L, Mennicken R, Scholtes S. Stress on the ward: evidence of safety tipping points in hospitals. Manage Sci. 2014;61:754-771.

23. Gu YR, Li CY. A survey of professional development status of intravenous infusion therapy in Beijing. J Nurs Admin. 2013;13:316-318 (in Chinese). 